\title{
Magnitude and Determinants of Self-Referral of Patients at a General Hospital, Western Ethiopia
}

\author{
Wolkite Olani Abdi ${ }^{1}$, Waju Beyene Salgedo ${ }^{2,}$, Gebeyehu Tsega Nebeb ${ }^{2}$ \\ ${ }^{1}$ Eastern Wellega, Oromia Regional State, Ethiopia \\ ${ }^{2}$ Department of Health Economics Management and Policy, College of Health Sciences, Jimma University, Jimma, Ethiopia
}

Email address:

wolkbek@gmail.com (W. O. Abdi),dagimwaju@yahoo.com (W. B. Salgedo), gebishts@gmail.com (G. T. Nebeb)

\section{To cite this article:}

Wolkite Olani Abdi, Waju Beyene Salgedo, Gebeyehu Tsega Nebeb. Magnitude and Determinants of Self-Referral of Patients at a General Hospital, Western Ethiopia. Science Journal of Clinical Medicine. Vol. 4, No. 5, 2015, pp. 86-92. doi: 10.11648/j.sjcm.20150405.12

\begin{abstract}
Background. Self-referrals may cause the primary level health care to be under-utilized and hospitals over used, congested and overburdened, leading to an escalation of health care costs. Large patient load in referral hospitals causes human and physical resources to be stretched to capacity, which results in compromising the quality of care they provide to patients. The aforementioned problem is well observed in the study area but the phenomenon has not been formally studied. Therefore, this study aimed to assess the magnitude and determinants of self-referral of patient to the secondary referral level. Method and materials: A hospital based cross sectional study was conducted from April 16-30, 2014. Four hundred twenty two patients were selected using systematic sampling technique. Data was collected using structured and pre-tested questionnaire. Six data collectors and one supervisor collected the data. Data was analyzed using SPSS for window version 20 computer software. Simple and multiple logistic regressions were used to measure the association of variables at 95 percent confidence interval and $\mathrm{p}$-value of $<0.05$. Ethical clearance was obtained from the ethics committee of the college of Health sciences, Jimma University, in Ethiopia. Result: A total of 422 patients responded to the interview making the response rate $99.8 \%$. Three hundred forty six (82\%) of the participants were self-referred among which $218(63.0 \%)$ were females. Three hundred and twenty two $(93 \%)$ of the self-referred patients bypassed the first rung in the referral ladder despite knowledge of the closer health facility as their first level of care. Those who obtained information on the referral system from health workers were 3.5 times less likely to self refer themselves to the general referral study Hospital. Conclusions: Obtaining laboratory test, availability of drugs at closer health facility, knowing the closer health facility is first referral level and obtaining health education on referral systems from health worker were found to be significantly associated with self-referral to Nekemte General Hospital. Thus it is recommended that the healthcare leaders should strive to ensure better availability of drug supply and laboratory tests at local health centers and health care providers should work hard to make their community aware of the referral system to get efficient and effective service at a closer heath facility.
\end{abstract}

Keywords: Self-Referral, Nekemte, Ethiopia

\section{Introduction}

Referral is a process by which a health worker transfers the responsibility of care temporarily or permanently to another health professional or social worker or to the community to obtain the consultation or special expertise directly needed (1). While self-referral is when patients self-refer themselves to a higher level healthcare facility other than the primary care facility closest to their residence with expectation of getting better care.

Self-referrals may cause the primary level health care to be under-utilized and hospitals over used, congested and overburdened, leading to an escalation of health care costs (2). It makes many patients spend long hours waiting to see highly trained medical workers in hospitals and lead to misapplication of the highly trained health workers' time for minor cases, which decreases the access to needy patients to see the highly trained health workers. in many situations, due to large patient loads, human and physical resources are stretched to capacity, which results in hospitals compromising the care that they provide to patients (2-4).

Studies from African countries show the higher sophistication of referral centers may result in patients bypassing lower levels of care and presenting themselves to 
higher levels irrespective of the triviality or seriousness of their medical complaint. Up to $82 \%$ of maternity hospital, users have been found to be self-referrals (2). Similarly, a study conducted in Sri Lanka shows, in the rural district close to $2 / 3$ of individuals seeking treatment-bypassed lower level facilities. In particular, the more severely ill patients were more likely to bypass lower level health facilities (5).

In a study done in Pakistan in 2001 to assess the reasons why patients by passed the first level care facilities (FLCF), $11 \%$ said that they were too ill and felt that they had to go to the higher level of care so as not to lose time (6). Another study in India showed that $55.7 \%$ of caretakers sought care directly at the referral facility because they perceived that the referral facility provided better quality services. In addition, Atkinson and colleagues found in urban Zambia, people sought care at hospital facilities, not for perceived improved quality services, but because they thought they were less costly and better stocked with drugs (7). In Tanzania patients bypassing nearby health centers to seek health care at distant hospitals and private facilities show that their behavior is tied to their understanding of various measures of quality at the facilities that they visit and bypass (8)

In Ethiopia, the government which is the main provider and financer of healthcare has established a three-tier health service delivery system, which requires an effective twoway referral connection (9). The national health policy has a strategy for development of an effective referral system which focuses on improving accessibility of care according to need, assuring continuity and improved quality of care at all levels, rationing costs for health care seekers and providers for optimal utilization of health care facilities at all levels and strengthening the communication within the healthcare system (10). With the recent accelerated expansion of primary health care facilities, the Ethiopian health system has addressed one of the most significant barriers to entry to the health system, the availability of basic care within a reasonable distance (11). Otherwise, the underutilization of services at most peripheral public facilities tend to continue, while at the same time patients incur unnecessary costs due to self-referral to distant and more expensive centers(12).

The aforementioned problem is well observed in the study area but the phenomenon has not been formally studied. Therefore, this study aimed to assess the magnitude and determinants of self-referral of patient to the secondary referral level.

\section{Methods and Materials}

This study was conducted April 16 - 30, 2014 at Nekemte general public hospital in east Wollega zone, western Ethiopia. The zone has one general public hospital, one primary public hospital and 58 health centers. Nekemte Hospital was expected to serve as a referral hospital for about 1.6 million people residing in the surrounding area.
A Cross sectional facility based study design that used quantitative method of data collection was employed. The Sample size was determined by single population proportion formula with assumption of $50 \%$ referral rate, $95 \%$ confidence interval with $5 \%$ margin of error plus $10 \%$ non-response rate. Patients with mental health problems, emergency cases and who were less than 15 years were excluded from inclusion. Each study subjected was identified by Systematic sampling technique by considering an average monthly patient flow of 6850 and calculating the sampling interval with $\mathrm{K}=\mathrm{N} / \mathrm{n}$ where $\mathrm{N}=3425, \mathrm{n}=423$ $\mathrm{K}=3425 / 423=8.1$, which led us to take every $8^{\text {th }}$ patient from the main registration office by selecting the first subject by lottery method.

The dependent variable of measurement was Self-referral to secondary referral level while the independent Variables were Patient related factors(Sociodemographic characteristics, Knowledge),Perceived severity of illness, Perceived quality of care at health facility and confidence of patients in care providers), primary health facility related factors(Accessibility, Availability of drug and services, comfort, cleanness and adequate space), referral facility related factors(Availability of drug and diagnostic Services) and Provider related factor (Availability and accessibility of preferred provider, Relationship status, Perceived technical competence).

A structured and Pre-test face-to-face interview questionnaire was used to collect data. One person was assigned to the record office to trace sampled patients by using a serial number from a registration book. Other data collectors who were assigned at each of six case team rooms interviewed the identified subject upon completion of the services.

Data were analyzed using SPSS version 20 software. Descriptive statistics of frequency was performed. Simple logistic regression was performed to identify association between variables. Variables with p-value less than 0.25 with simple logistic regression were entered into multiple logistic regression to determine predictors of self-referral at p-value 0.05 significance level.

Ethical clearance was obtained from the ethics committee of college Health sciences, Jimma University. Verbal informed consent was obtained from each study participants and all information was kept confidential.

\section{Results}

Among the total 423 study subjects, 422 responded to the interview making the response rate $99.8 \%$. Three hundred and forty six $(82 \%)$ were self-referred patients and $218(51.7 \%)$ were female. The median age of study subjects was 32 years with range of 17 to 84 years. The majority (37\%) of respondents were in the age group of 25-34 years; $340(80.6 \%)$ were married, $179(42.4 \%)$ were farmers and109 (25.8\%) of respondents were 9-12 grade educated Table 1). 
Table 1. Sociodemographic characteristics, Nekemte General Hospital, April 2014.

\begin{tabular}{|c|c|c|c|}
\hline \multirow{2}{*}{ Variables } & \multicolumn{3}{|l|}{ Self referred } \\
\hline & Yes $(n=346) N(\%)$ & No $(n=76) N(\%)$ & Total $(n=422) N(\%)$ \\
\hline \multicolumn{4}{|l|}{ Sex } \\
\hline male & $177(51.16 \%)$ & $27(35.53 \%)$ & $204(48.3 \%)$ \\
\hline female & $169(48.84 \%)$ & $49(64.47 \%)$ & $218(51.7 \%)$ \\
\hline \multicolumn{4}{|l|}{ Age } \\
\hline $17-24$ & $51(14.74 \%)$ & $8(10.53 \%)$ & $59(14 \%)$ \\
\hline $25-34$ & $125(36.13 \%)$ & $31(40.79 \%)$ & $156(37 \%)$ \\
\hline $35-44$ & $106(30.64 \%)$ & $21(27.63 \%)$ & $127(30 \%)$ \\
\hline$>=45$ & $64(18.5 \%)$ & $16(21.05 \%)$ & $80(19 \%)$ \\
\hline \multicolumn{4}{|l|}{ Marital status } \\
\hline Single & $42(12.14 \%)$ & $11(14.47 \%)$ & $53(12.6 \%)$ \\
\hline married & $284(82.08 \%)$ & $56(73.68 \%)$ & $340(80.6)$ \\
\hline divorced & $14(4.05 \%)$ & $5(6.58 \%)$ & $19(4.5 \%)$ \\
\hline widowed & $6(1.73 \%)$ & $4(5.26 \%)$ & $10(2.4 \%)$ \\
\hline \multicolumn{4}{|l|}{ Educational status } \\
\hline Unable to read \& write & $76(21.97 \%)$ & $6(7.89 \%)$ & $82(19.4 \%)$ \\
\hline Only read \&write & $65(18.77 \%)$ & $19(25 \%)$ & $84(19.9 \%)$ \\
\hline Grade 1-8 & $61(17.63 \%)$ & $14(18.42 \%)$ & $75(17.8 \%)$ \\
\hline Grade $9-12$ & $84(24.285)$ & $25(32.89 \%)$ & $109(25.8)$ \\
\hline$>12$ & $60(17.34)$ & $12(15.79 \%)$ & $72(17.1 \%)$ \\
\hline \multicolumn{4}{|l|}{ Occupational status } \\
\hline Government employee & $87(25.14 \%)$ & $25(32.89 \%)$ & $112(26.5 \%)$ \\
\hline Merchant & $55(15.9 \%)$ & $18(23.68 \%)$ & $73(17.3 \%)$ \\
\hline Farmer & $155(44.8 \%)$ & $24(31.58 \%)$ & $179(42.4 \%)$ \\
\hline House wife & $19(5.49 \%)$ & $6(7.89 \%)$ & $25(5.9 \%)$ \\
\hline others & $30(8.67 \%)$ & $3(3.95 \%)$ & $33(7.8 \%)$ \\
\hline
\end{tabular}

Others- student, daily laborer, waiter and barber.

With regard to the patients' experience at the closer health facility, 309(73.9\%) said that the type of provider they wanted was not available. Three hundred seventy three (88.4\%) respondents said that they had no access to the type of provider they want. The majority of respondents $370(87.7 \%)$ declared that they preferred to see a general medical doctor $(\mathrm{GP})$ at closer health facility. Three hundred twenty three (76.5\%) of respondents said that providers at closer health facility did not explain medical information in a way they understand and 326 (77.3\%) of respondents said providers at closer health facility did not provide full information about their health problem (Table 2).

Table 2. Patients' experience at closer health facility for self-referral, Nekemte General Hospital, Western Ethiopia, April 2014.

\begin{tabular}{|c|c|c|c|}
\hline \multirow{2}{*}{ Variables } & \multicolumn{3}{|l|}{ Self-referral } \\
\hline & Yes N(\%) & No N(\%) & Total N(\%) \\
\hline \multicolumn{4}{|c|}{ Visit in last 12 months } \\
\hline Yes & $335(96.8 \%)$ & $70(92.1 \%)$ & $405(96 \%)$ \\
\hline No & $11(3.2 \%)$ & $6(7.9 \%)$ & $17(4 \%)$ \\
\hline \multicolumn{4}{|c|}{ Availability of provider patient want } \\
\hline Yes & $69(20.6 \%)$ & $25(36.8)$ & $96(23.7 \%)$ \\
\hline No & $266(79.4 \%)$ & $43(63.2)$ & $309(76.3 \%)$ \\
\hline \multicolumn{4}{|c|}{ Access to provider patient prefer } \\
\hline Yes & $23(6.87 \%)$ & $9(12.86 \%)$ & $32(7.9 \%)$ \\
\hline No & $312(93.13 \%)$ & $61(87.14 \%)$ & $373(92.1 \%)$ \\
\hline \multicolumn{4}{|c|}{ Listened carefully to patient } \\
\hline Yes & $192(57.3 \%)$ & $60(85.71 \%)$ & $252(62.22 \%)$ \\
\hline No & $143(42.7 \%)$ & $10(14.29 \%)$ & $153(37.78 \%)$ \\
\hline \multicolumn{4}{|c|}{ Courtesy and respect } \\
\hline Yes & $147(43.88 \%)$ & $60(85.71 \%)$ & $207(51.11 \%)$ \\
\hline No & $188(56.12 \%)$ & $10(14.29 \%)$ & $198(48.89 \%)$ \\
\hline \multicolumn{4}{|c|}{ type of provider patient prefer } \\
\hline GP Doctor & $317(94.63 \%)$ & $53(75.71 \%)$ & $370(91.36 \%)$ \\
\hline $\mathrm{HO} / \mathrm{Bsc}$ nurse & $2(0.60 \%)$ & $0(0)$ & $2(0.49 \%)$ \\
\hline specialist & $16(4.77 \%)$ & $17(24.29 \%$ & $33(8.15 \%)$ \\
\hline \multicolumn{4}{|c|}{ explained in ways you understands } \\
\hline Yes & $66(19.70 \%)$ & $16(22.86)$ & $82(20.25 \%)$ \\
\hline
\end{tabular}




\begin{tabular}{llll}
\hline \multirow{2}{*}{ Variables } & Self-referral & & No N(\%) \\
\cline { 2 - 4 } & Yes N(\%) & $54(77.14 \%)$ & $323(79.75 \%)$ \\
\hline No & $269(80.30 \%)$ & & $79(19.51 \%)$ \\
Provided full information & & $15(21.43 \%)$ & $326(80.49 \%)$ \\
Yes & $64(19.10 \%)$ & $55(78.57 \%)$ & \\
No & $271(80.90 \%)$ & & \\
\hline
\end{tabular}

N.B: The reason for difference in sample size is due the fact that not all 422 had a visit their closer health facilities before 12 months of the survey. The patients who had visited their closer facilities were only 405, of which 335 were self referred to the general hospital and 70 were not.

A total of 368 respondents visited the closer health facility for their current health problem among which 292(79.3\%) then self-referred themselves to the study hospital. Two hundred sixty one $(70.9 \%)$ perceived that provider at the closer health facility had no experience with their medical problem. Three hundred twelve $(84.8 \%)$ of those who had history of a visit at closer health facility for their current health problem perceived that providers at closer health facility did not fully explain their health problems. Regarding perceived technical competence $307(83.4 \%$ ) of respondents perceived that providers at closer health facility did not examine them thoroughly (Table 3 ).

Table 3. Patients' perception on technical competence of providers at closer health facility, Nekemte general hospital, western Ethiopia, April 2014.

\begin{tabular}{|c|c|c|c|}
\hline \multirow{2}{*}{ Variables } & \multicolumn{3}{|l|}{ Self referred } \\
\hline & Yes N (\%) & No N (\%) & Total N (\%) \\
\hline \multicolumn{4}{|c|}{ Provider Experience } \\
\hline Yes & $93(31.8 \%)$ & 14(18.4) & $107(29.1)$ \\
\hline No & $199(68.2 \%)$ & $62(81.6)$ & $261(70.9)$ \\
\hline \multicolumn{4}{|c|}{ Provider explanation } \\
\hline Yes & $27(9.2 \%$ & $29(38.2 \%)$ & $56(15.2)$ \\
\hline No & $265(90.8 \%)$ & $47(61.8 \%)$ & $312(84.8)$ \\
\hline \multicolumn{4}{|c|}{ Carefully checked every thing } \\
\hline Yes & $30(10.3 \%)$ & $20(26.3 \%)$ & $50(13.6)$ \\
\hline No & $262(89.7 \%)$ & $56(73.7 \%)$ & $318(86.4)$ \\
\hline \multicolumn{4}{|c|}{ examined you thoroughly } \\
\hline Yes & $36(12.3 \%)$ & $25(33)$ & $61(16.6)$ \\
\hline No & $256(87.7 \%)$ & $51(67)$ & $307(83.4)$ \\
\hline
\end{tabular}

Regarding patient perception of quality of service at the closer health facility, $312(74 \%)$ of respondents said that they had no confidence that they would get the right provider. Three hundred nine (73.2\%) responded that they had no confidence that they would get the drugs at the closer health facility. Regarding confidence in laboratory service
$355(84 \%)$ of respondents responded that they had no confidence that they would get the laboratory service at the closer health facility and $305(72.3 \%)$ of total respondents cited that they do not recommend care at closer health facility for someone else (Table 4).

Table 4. Patient perception on quality of care at closer health facility, Nekemte general hospital, western Ethiopia, April 2014.

\begin{tabular}{|c|c|c|c|}
\hline \multirow{2}{*}{ Variables } & \multicolumn{3}{|c|}{ Self-referral } \\
\hline & Yes N (\%) & No N (\%) & Total N (\%) \\
\hline \multicolumn{4}{|l|}{ confidence of getting provider } \\
\hline Yes & $58(16.8)$ & $52(68.4)$ & $110(26)$ \\
\hline $\begin{array}{l}\text { No } \\
\text { confidence of getting drug }\end{array}$ & $288(83.2)$ & $24(31.6)$ & $312(74)$ \\
\hline Yes & $77(22.3)$ & $36(47.4)$ & $113(26.8)$ \\
\hline $\begin{array}{l}\text { No } \\
\text { confidence on lab service }\end{array}$ & $269(77.7)$ & $40(52.6)$ & $309(73.2)$ \\
\hline Yes & $20(5.8)$ & $47(61.8)$ & $67(16)$ \\
\hline $\begin{array}{l}\text { No } \\
\text { recommend care to someone else }\end{array}$ & $326(94.2)$ & $29(38.2)$ & $355(84)$ \\
\hline Yes & $71(20 . \%)$ & $46(60.5)$ & $117(27.7)$ \\
\hline No & $275(79 . \%)$ & $30(39.5)$ & $305(72.3)$ \\
\hline
\end{tabular}

Table 5 shows the knowledge of patients regarding service at the closer health facility and referral system. Accordingly, $274(65 \%)$ responded that they did not know that their health center or primary hospital was the first referral level. $273(64.7 \%)$ responded that they don't know the availability of appropriate laboratory services. With regard to knowledge about the availability of appropriate providers at closer health facility $323(76.5 \%)$ responded that they did not know about it and $350(82.9 \%)$ of respondents responded that they were not provided any information about the referral system 
(Table 5).

Table 5. Knowledge of patients on health services at closer health facility and perceived severity of illness, Nekemte general hospital, western Ethiopia, April 2014.

\begin{tabular}{llll}
\hline \multirow{2}{*}{ Variable } & Self-referral & & Total N (\%) \\
\cline { 2 - 3 } $\begin{array}{l}\text { Closer health facility is first contact } \\
\text { Yes }\end{array}$ & & No N (\%) & $148(35 \%)$ \\
No & $87(25.1 \%)$ & $61(80.3 \%)$ & $274(65 \%)$ \\
know the type of lab service & $259(74.9 \%)$ & $15(19.7 \%)$ & $149(35.3 \%)$ \\
Yes & $91(26.3 \%)$ & $58(76.3 \%)$ & $273(64.7 \%)$ \\
No & $255(73.7 \%)$ & $18(23.7 \%)$ & $99(23.5 \%)$ \\
know the type of provider available & & $36(47.4 \%)$ & $323(76.5 \%)$ \\
Yes & $63(18.2 \%)$ & $40(52.6 \%)$ & $72((17.1 \%)$ \\
No & $283(81.8 \%)$ & & $350(82.9 \%)$ \\
Yes & & $20(26.3 \%)$ & \\
No & $52(15 \%)$ & $56(73.7 \%)$ & $329(78)$ \\
$\begin{array}{l}\text { Perceived severity of illness } \\
\text { mild }\end{array}$ & $294(85 \%)$ & $46(60.5)$ & $26(6.1)$ \\
\hline
\end{tabular}

Association of self referral with independent variables

To identify the association between dependent and independent variables, we entered each variable independently and then taken variables with p-value less than 0.25 into multiple logistic regression. Table 7 below shows the association between the variables. Accordingly, the result showed that sex was significantly associated with selfreferral (AOR and 95\% CI $=0.494(0.280-0.870)$. Similarly, knowing that the closer health facility was first referral level and obtaining information on the referral system from healthcare workers at the closer health facility were significantly associated with self referral to secondary hospital (AOR and 95\% CI $=0.24[(0.164,0.317)$ and 0.65 $(0.467,0.791)]$ respectively. Moreover, obtaining laboratory test service at the closer health facility was also found to be significantly associated with self-referral status (AOR and $95 \%$ CI $=1.64(1.37,3.49)$. The result also showed that patients who had got some information and those who had got no information at all information about the prescribed drugs were 1.35 and 2.38 times more likely to self refer themselves to the next higher level care respectively as compared with those respondents who obtained full information about their prescribed drugs (AOR and 95\% CI $=1.35(1.08,3.44)$ and $2.38(2.19,3.77)$ respectively.

The study showed that patients who knew that the closer health facility was the first referral level were $76 \%$ less likely to self refer themselves to Nekemte General Hospital and those who obtained information on the referral system from any healthcare worker at the closer health facility were $35 \%$ less likely to self refer.

With the reference group who obtained all of laboratory test service at the closer facility, those who obtained none of laboratory test at closer health facility were 1.64 times more likely to self refer. Also obtaining prescribed drugs at the closer health facility was found to significantly associated with self-referral (Table 6).

Table 6. Predictors for self-referral, Nekemte general hospital, western Ethiopia, April 2014.

\begin{tabular}{|c|c|c|c|c|c|}
\hline \multirow{2}{*}{ Variables } & \multicolumn{3}{|l|}{ Self-referral } & \multicolumn{2}{|l|}{ OR and $95 \%$ CI } \\
\hline & Yes N (\%) & No N (\%) & Total N (\%) & univariate & multiple \\
\hline \multicolumn{6}{|l|}{ Sex } \\
\hline male* & $177(51.16)$ & $27(35.53)$ & $204(48.3)$ & 1 & 1 \\
\hline female & $169(48.84)$ & $49(64.47)$ & $218(51.7)$ & $0.539(0.327-0.915)$ & $0.494(0.280-0.870)$ \\
\hline \multicolumn{6}{|l|}{ Educational status } \\
\hline Unable to read \& write & $76(21.97 \%)$ & $6(7.89 \%)$ & $82(19.4 \%)$ & $2.533(0.898-7.144)$ & $0.524(0.145,1887)$ \\
\hline Only read \&write & $65(18.77 \%)$ & $19(25 \%)$ & $84(19.9 \%)$ & $0.684(0.306-1.528)$ & $0.314(0.52,1.888)$ \\
\hline Grade $1-8$ & $61(17.63 \%)$ & $14(18.42 \%)$ & $75(17.8 \%)$ & $0.871(0.373-2.038)$ & $0.948(0.49,18.419)$ \\
\hline Grade 9-12 & $84(24.285)$ & $25(32.8)$ & $109(25.8)$ & $0.672(0.313-1.443)$ & $0.70(0.13,0.365)$ \\
\hline$>=12 *$ & $60(17.34)$ & $12(15.7)$ & $72(17.1)$ & 1 & 1 \\
\hline \multicolumn{6}{|c|}{ Closer health facility is first contact } \\
\hline Yes & $87(25.1)$ & $61(80.3)$ & $148(35)$ & $0.46(0.29-1.91)$ & $0.24(.16-0.32)$ \\
\hline No* & $259(74.9)$ & $15(19.7)$ & $274(65)$ & 1 & 1 \\
\hline \multicolumn{6}{|l|}{ Information on referral } \\
\hline Yes & $52(15)$ & $20(26.3)$ & $72(17.1)$ & $0.37(0.27-0.54)$ & $0.65(0.47-0.79)$ \\
\hline No* & $294(85)$ & $56(73.7)$ & $350(82.9)$ & 1 & 1 \\
\hline \multicolumn{6}{|c|}{ Perceived severity of illness } \\
\hline sever & $283(81.8)$ & $46(60.5)$ & $329(78)$ & $5.21(0.95-4.28)$ & $2.17(1.06-5.83)$ \\
\hline mild* & $18(5.2)$ & $8(10.5)$ & $26(6.1)$ & 1 & 1 \\
\hline \multicolumn{6}{|l|}{ Laboratory test (312) } \\
\hline Obtained all* & $51(21.1)$ & $11(15.5)$ & $62(19.9)$ & 1 & 1 \\
\hline
\end{tabular}




\begin{tabular}{|c|c|c|c|c|c|}
\hline \multirow{2}{*}{ Variables } & \multicolumn{3}{|c|}{ Self-referral } & \multicolumn{2}{|l|}{ OR and $95 \%$ CI } \\
\hline & Yes N (\%) & No N (\%) & Total N (\%) & univariate & multiple \\
\hline obtained None & $72(29.9)$ & $32(45.1)$ & $104(33.3)$ & $1.94(1.67-4.03)$ & $1.64(1.37-3.49)$ \\
\hline obtained Some & $118(49)$ & $28(39.4)$ & $146(46.8)$ & $1.29(.05-3.85)$ & $1.82(0.29-2.73)$ \\
\hline \multicolumn{6}{|l|}{ Drugs (368) } \\
\hline Obtained all* & $76(26)$ & $11(15.1)$ & $87(23.6)$ & 1 & 1 \\
\hline obtained None & $111(38)$ & $19(26)$ & $130(35.3)$ & $3.86(1.93-6.14)$ & $2.38(2.19-3.77)$ \\
\hline obtained some & $105(36)$ & $46(58.9)$ & $151(41.1)$ & $2.18(1.25-5.19)$ & $1.35(1.08-3.44)$ \\
\hline
\end{tabular}

N.B: The reason for difference in sample size is due to the fact that not all 422 had a visit their closer health facilities before 12 months of the survey. The patients who had visited their closer facilities were only 405, of which 335 were self referred to the general hospital.

\section{Discussion}

The magnitude of self-referral at Nekemte General Hospital was $82 \%$ that bypassed the first level referral facility. This finding is lower than a finding in Nigeria that showed a $93 \%$ self-referral rate (1). This difference could be attributed to the difference in the study population and design.

Among Sociodemographic characteristics, only Sex and educational status of the respondents were significantly associated with self-referral. We found that females were less likely to self refers (AOR 0.494). This implies that females were $50.6 \%$ less likely to self refer themselves to higher level. This difference might be related to the less decisionmaking power women on household economy as the society privileges males for most of the household expenses including healthcare costs. On the other hand, patients with an educational status of grade 9-12 were 2.68 times more likely to self refer (AOR 2.68 ) when compared to more educated patients. This is different from the Nigerian study that showed both the educated and uneducated bypass the lower levels of healthcare (2).

This study also showed that those who had not gotten laboratory orders were more likely to self-refer than those who obtained laboratory orders. This is Similar to a study done in Tanzania that showed lack of diagnostic facilities at PHC facilities was the main reason given for self-referral (13).

At the same time $38 \%$ of the self-referred patients had not got drugs prescribed at closer health facility. This is also similar with studies in Tanzanian (13) and in Kenya; both showed that dissatisfaction with the shortage of medicines in facilities affects health-seeking behavior (14).

The health centers and primary hospital are supposed to be the point of first contact for patients but $65 \%$ of respondents in this study did not know about this process because of a lack of information on the referral system from healthcare providers.

Illness perception of the patient is also an important factor for affecting the health seeking behavior. This study showed that patients who perceived that their illness as more severe were more likely to self-refer. This is supported by a study conducted in Sri Lanka, which also showed the relationship between severity of illness and bypassing facilities (6).

In summary, the magnitude of self-referral at Nekemte general hospital was found to be high with assumption that the primary level health care facilities are supposed to be the first level contact for all patients. The main reasons why patients self-referred to secondary hospital were found to be perceive lack of or poor quality of laboratory tests and drugs in addition to lack of information about the referral link in the health service system. Thus it is recommended that the responsible bodies should strive to equip the primary level facilities with standard laboratory equipment and drug supplies. The healthcare workers at different levels should give more attention to improve community awareness of patient referral system and its advantages. A wider scope study is warranted on impact of self-referral on service seekers and on health service system.

\section{Abbreviations}

FLCF- First level care facilities

GP- General medical doctor

\section{Authors' contributions}

We, the three, have significant contribution in the proposal development, defending for fund obtaining, data collection and data analysis and manuscript preparation process of this work.

\section{Acknowledgements}

I would like to thank Jimma University for funding this research. Our gratitude goes to heads of Nekemt general Hospital, all data collectors, supervisors, data manager and study participants for their cooperation in the study process.

\section{References}

[1] Akande TM. Referral system in Nigeria: a study of tertiary health facility. Annuals of African Medicine 2004.

[2] Murray SF, Pearson SC. Maternity referral systems in developing countries: current knowledge and future research needs. Social Science \& Medicine 2006; 62(9): 2205-2215.

[3] Mahlmeister, L. The process of triage in perinatal settings: clinical and legal issues. J Perinat Neonatal Nurs. 2002; 13:13-30.

[4] Osibogun A. The role of health center in the rational use of health resources. Paper presented at the 17th Annual Scientific Conference of Association of Community Physicians of Nigeria. March 1996. 
[5] Akin, John and Paul Hutchinson (1999) "Health-care Facility Choice and the Phenomenon of Bypassing", Health Policy and Planning, 14 (2): 135-51.

[6] S Siddiqi, AA Kielmann, Ms Khan, et al. The effectiveness of patient referral in Pakistan. Health Policy and Planning 2001; 16: 193-198.

[7] Atkinson $\mathrm{S}$ et al. The referral process and urban care in subSaharan Africa: The case of Lusaka, Zambia (1999). 49(1):27-38.

[8] Leonard K, Mliga G, Haile Mariam D. Bypassing health centers in Tanzania: Revealed preferences for observable and unobservable quality. Journal of African Economies 2002; 11 (4):441-471.

[9] Federal Ministry of Health. Health service Development program IV.Addis Ababa Ethiopia 2010.
[10] Federal Ministry of Health. Health policy of the Transitional government of Ethiopia, Sept 1993.

[11] Federal Ministry of Health, Ethiopia: Policy, Planning and Finance General Directorate. The 2008/09 Annual Review Meeting (ARM) Performance Report. 2010. Addis Ababa, Ethiopia.

[12] Haile Mariam D. Bridging the availability-utilization gap: The issue of quality in the provision of health care. Addis Ababa, Ethiopia Ethiop J Health Dev 2011; 25(1).

[13] Kahabuka C, Kvåle G, Karen MM, Sven GH. Why caretakers bypass Primary Health Care facilities for child care. Tanzania 2011.

[14] Turin, Dustin R. Health Care Utilization: Analyzing the Kenyan Health System. Student Pulse Academic Journal $2010 ; 2.09$. 